CHAPTER III

\title{
TWENTY SEVENTH GENERAL ASSEMBLY CLOSING CEREMONY
}

Thursday 13 August 2009, $15.45-17.00$

Centro de Convenções SulAmérica, Rio de Janeiro

\section{In honour of Francisco Xavier de Araújo}

Address by Professor Daniella Lazzaro

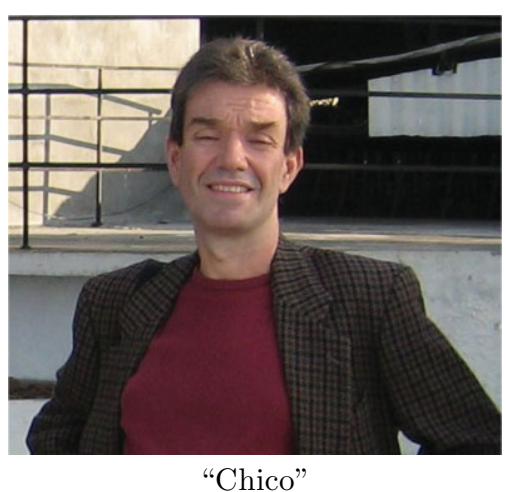

On behalf of the National Organizing Committee, the IAU Executive Committee and all the Brazilian astronomical community I am here now to honor the memory of our dearest friend and member of the NOC, Dr. Francisco Xavier de Arajo, who passed away just one month ago.

Dr. Francisco, or Chico as was known by his friends, is the person who has been working for this meeting from the very first moment.

Since the end of 2002, when we started preparing the bid to host the GA here in Rio, up to few weeks ago, Chico has been the heart of the organization. His kindness, his natural skill in negotiation, his high commitment to the success of the meeting made him fundamental to the organization.

Although very difficult for us, we are here because this is what he would have wanted: for us to continue and turn into reality the dream of the Brazilian astronomical community to host an IAU GA.

Thank you, Chico, we miss you so much! 


\title{
2. IAU Strategic Development Plan
}

Address by Vice-President Professor George K. Miley

On behalf of the Executive Committee and particularly of Bob Williams and Catherine Cesarsky, I thank you for passing the two resolutions endorsing our new decadal strategic plan "Astronomy for the Developing World".

I have described the plan at length on several occasions during this General Assembly and I shall not repeat this description here. The plan is an ambitious flexible and credible blueprint for using astronomy to stimulate sustainable global development. It contains a long term vision, achievable goals and a comprehensive new strategy for attaining these goals. An important element of the strategy is a regional bottom-up approach. The plan will be implemented with an effective and lean organisational structure subject to professional oversight.

Passing the resolutions is only the beginning. Now comes the hard work and I ask you to help with this. Please go home and discuss the plan with the directors of your institutes and the governing bodies of your universities. Is your institute willing to participate in a longterm twinning scheme with a physics department in a developing country or to fund your staff to give inspirational lectures in a poorer region of the world? Would your department be prepared to function as a regional node or maybe even provide matching funds and host the new Global Astronomy for Development Office? In seeking funding for such activities, please talk to your governments. The rationale for development activities is relevant to government departments, that you may not ever have approached before, such as Ministries of International Development or Foreign Affairs. Maybe a bilateral treaty involving your country could be used to fund astronomy development activities. If we in the IAU can help you in these fund raising activities, please let us know.

In seeking resources for the plan we must be creative. Among the organisations and people to approach are international and national development foundations, multinational companies operating in developing countries, international and regional development agencies and credible philanthropists.

I now address those of you who are involved in proposing new astronomical facilities, on the ground and in space. When writing your proposals, please consider earmarking a few percent of the budget for astronomy development programmes. Devoting a tiny fraction of astronomical resources to global development and education enhances the image of astronomy as a whole and make politicians more receptive to astronomy research proposals.

As we embark on raising funds in support of the plan, it is important to have strong arguments ready to use. In her beautiful address at the opening of this General Assembly Catherine Cesarsky touched on a few of the reasons why astronomy is of benefit to society. The closing ceremony is a fitting time to summarise more generally the rationale for astronomy presented in our plan and illustrated on its front and back covers.

Astronomy provides an inspirational and unique gateway to technology science and culture, three fundamental characteristics of developed nations.

\section{Invitation to XXVIII General Assembly, Beijing, China August 2012}

\author{
Address by President of Chinese Astronomical Society Professor Gang Zhao
}

It is my great pleasure to be here with you on this most important gathering in the world of astronomy, the IAU 27th GA in Brazil, and to say a few words on behalf of the Chinese Astronomical Society.

First, I would like to thank the International Astronomical Union, as well as the organizing committee of this assembly, for hosting such a grand meeting, and giving us this honorable opportunity to present our warm invitation for attending next IAU GA in Beijing, China. Being the capital of China, Beijing is well-known as a fast-growing, dynamic international metropolis 
with 3,000 years' history. It is one of the safest and the most peaceful cities in the world. The long history leaves Beijing precious cultural treasure, among which four sites have been designated as world cultural heritage by UNESCO: the Great Wall, the Summer Palace, the Forbidden City, and the Temple of Heaven. As Beijing will be the host city of the next IAU GA in 2012, the spirit of IAU will definitely promote the development of astronomy in China as well as in the world, and strengthen the friendship of our IAU family.

Since the adoption of 'open door policy' in the past 30 years, especially the last decade, great advance has been achieved in astronomical studies in China. We are now getting ready to present a memorable General Assembly for astronomers all over the world. With natural beauty, rich history and diverse culture, Beijing opens her arms to welcome your arrival in August of 2012!

Welcome to Beijing! Welcome to next IAU GA! Thank you!

Professor Gang Zhao then showed a short video illustrating the attractions of Beijing as a venue for an IAU General Assembly.

\section{Address by retiring General Secretary, International Astronomical Union}

Dr. Karel A. van der Hucht

The International Astronomical Union has been founded in Brussels 90 years ago, with as its mission to foster collaboration among scientists in the world. Young in comparison to the world's oldest science, the IAU is still sufficiently long-lived to have a rich tradition. I am pleased to be part of this venerable heritage. I have strived these past three years to serve you as General Secretary.

I give you three good reasons why I have enjoyed being your General Secretary.

- Trained as a research astronomer and specializing in the astrophysics of Wolf-Rayet stars, I used to focus my research mostly to that field, observing at all wavelengths from the ground and from space. Between 1990 and 2002 I helped organizing, among other things, four IAU Symposia in that field, and editing the proceedings. That may have been why someone suggested me for IAU General Secretary. Working for the IAU as General Secretary brought me in touch with colleagues working in all fields of astronomy. That enriched my life.

- I had the privilege to work with very motivated and dedicated fellow Officers and fellow EC members. That made my job as General Secretary very gratifying.

- Working for the IAU Secretariat as General Secretary means working for three years parttime in Paris: a rare opportunity to familiarize with a beautiful and fascinating city. However, due to circumstances beyond my control, I saw mostly the walls of my office at the IAU Secretariat. My wife got to see Paris. That's fine too.

Stating that by now I know all about the IAU may be too far fetched. In a Union with 63 National Members, over 10000 Individual Members organized in 12 Divisions, 40 Commissions and 75 Working Groups and Program Groups, there is always more to learn. The closest in getting to know the IAU is doing the editing of the General Secretary's trilogy: the Highlights of Astronomy, the Proceedings of the General Assembly (Transactions B), and the Reports of Astronomy (Transactions A). These volumes may be referred to by some of you as the books which no body reads, but editing them was for me an extremely useful and revealing exercise to get informed about the activities of the IAU membership.

Three years seem a long period in the beginning, but really feel like a short stretch at the end. The period from August 2006 to August 2009 was continuously dominated by expected and unexpected serious activities and developments. There is much to be grateful for and there are many to be grateful to. My sincere thanks go to: - my home institute SRON in Utrecht, the Netherlands, for giving me leave of absence for effectively 4.5 years, to work as AGS and as GS for the 
IAU; - my fellow Officers Catherine Cesarsky, Bob Williams and Ian Corbett. In the past three years we have shared much of our work for the IAU, leading to a fruitful and effective cooperation; - all preceding General Secretaries, who were always there to give advice in a most constructive way; - the staff of the IAU Secretariat in Paris, in particular my Executive Assistant Mme Vivien Reuter. Mme Reuter joined the Secretariat at a very difficult time. Together we had to re-invent the Secretariat, often hanging on by our fingernails, but surviving. Vivien, without you the IAU Secretariat would not be in the good shape as it is today. You are for me formedable. - and our very motivated National Organizing Committee for this IAU XXVII General Assembly, co-chaired by Daniela Lazzaro and Beatriz Barbuy, who have invited us to this beautiful city, Rio de Janeiro, and who made the General Assembly happen. We would not be here without their intense efforts. But most of all I want to thank my wife Ritte.

\title{
5. Address by the incoming General Secretary
}

\author{
Dr. Ian F. Corbett
}

It is a great honour and a great challenge to be elected as General Secretary of the IAU, and I thank you most sincerely for your confidence. I greatly enjoyed my three years as Assistant General Secretary and I must thank publicly all the organisers, authors and especially editors of the 27 Symposia and 4 Regional Meetings held during my term of office. I also extend a warm welcome to the new AGS, Thierry Montemerle, and assure him that he will find the next three years interesting and rewarding.

Needless to say, I am very much looking forward to the next three years. I must, however, start by saying a few words of thanks to Karel, whose exemplary commitment and tireless dedication as General Secretary for the past three years has ensured that the Union survived major upheaval in the Paris Secretariat, emerging stronger and fitter as a result. We owe him a great debt of gratitude. I am doubly grateful, of course, because not only do I benefit as an ordinary IAU member but as incoming General Secretary I inherit a very healthy state of affairs and an extremely competent assistant in Vivien Reuter, whom you have all seen actively helping to run this GA with her assistant Jana. Thank you, Karel, for making my task so much easier, and for being such a diligent mentor over the past three years.

I should also say a word or two of appreciation for our outgoing President, Catherine Cesarsky, who has been the driving force - and the clich is truly appropriate in this case - behind the International Year of Astronomy. This is proving an outstanding world-wide success, perhaps more than we could ever have hoped, and is due to the hard work and dedication of many people all over the world, and particularly the IYA Secretariat hosted by ESO. However, Catherine, you led from the front in shaping the objectives, the strategy and the structure of IYA, and I think we can all agree that it could never have been the same with without you.

We should now look to the future. I think that three - or possibly four - known challenges face us in my term as General Secretary. Fortunately for me, we have an outstanding new President and Executive Committee, and I thank them all for agreeing to serve.

First of all, we must strive to implement the Strategic Plan so eloquently presented a few minutes ago by George Miley. Secondly, we must ensure that the International Year leaves a deep and lasting legacy. IYA has been, and continues to be, an unprecedented success - we have seen original and creative activities all over the world and witnessed the profound effect on public awareness. We are taking 'astronomy' into the lives of many people to "engage a personal sense of wonder and discovery", we are promoting astronomy with amazing success in developing nations, and we have brought the wonder of the telescope into the lives of hundreds of thousands of children - and adults, too. We must follow this up through the continuing work of the IYA Secretariat and, most importantly, nationally through the initiatives and structures established during the IYA. I know that work to build this legacy has already started, and I am confident that we will succeed. 
The third challenge is more open ended - the IAU must continue to develop, to evolve, to adapt, but - above all - it must continue to reflect the needs and aspirations of its community. As Ron Ekers said in his opening address in Prague three years ago, "the IAU really works in the background to provide the lubrication for the wheels of the international machinery and international science". This is very much as it should be, but at the same time the IAU must achieve what I would call 'responsive leadership'. We need the active support and input of our National Members, who are far more than just our paymasters. We exist because we add value to what is being done in our National Members. We also depend very much on our Divisions and Commissions, and on their Presidents, Organising Committees, and members. These are the arteries and the nervous system of the Union. Through them, the Union moves forward and keeps in touch with the working astronomer, world-wide. I am confident that our new Division and Commission Presidents will rise to the challenge.

The fourth challenge may not be such a challenge after all. We have our next General Assembly in Beijing in 2012. We will have to match the very high standard set by our Brazilian hosts and Karel in organising this General Assembly. Yet such is my confidence in Professor Gang Zhao and his colleagues that I am sure we can all look forward to meeting again in Beijing in 2012, and in the course of another memorable General Assembly look back on a further three years of progress.

This has been a tremendous General Assembly and 2009 will be a momentous year in the history of the IAU. I thank you all, and I look forward to seeing you in Beijing.

\section{Address by the retiring President}

\section{Dr. Catherine J. Cesarsky}

For the 90th anniversary of IAU, the Secretary General has collected the memories of six past Presidents of the IAU in the Information Bulletin 104. Like them, I can state with confidence that being an IAU President is a light job: the entire burden of running IAU falls upon the General Secretary. I was fortunate in that "my" General Secretary was Karel van der Hucht, whose dedication to the union has been total. We suffered a bad blow when IAU Executive Assistant Monique Orine died in January 2008, leaving the office in a difficult situation. Luckily, we hired almost immediately Vivien Reuter to replace Monique, and Karel and Vivien together have orchestrated a fantastic recovery.

Like Karel and Ian, I can rejoice retrospectively at the excellent working atmosphere prevailing in our little group of Officers, as well as in the Executive Committee and also with the experienced Chair of the Finance sub-Committee, Paul Murdin, who has really been there for us in the hour of need. The Vice Presidents have each agreed to carry out a specific task for the Union. George Miley spearheaded the IAU Decadal Plan for Astronomy for the developing world; it remains for Bob and Ian, and then Norio and Thierry, to bring it to fruition: in particular to undertake the difficult task of raising the necessary funds, and, if possible, generate a generous host for the Global development office. Note that this plan covers only one subset of IAU activities, so there is more strategic thinking ahead; in fact, strategic plans always need to be reconsidered and adapted, but they remain an excellent method to trigger meaningful changes.

Like Karel, I have learnt a lot about the IAU these three years, and the more I know, the more I find the Union interesting and useful. I had a number of new experiences: I have taken part in a teaching venture in Kathmandu, and found it extremely gratifying. I advise all of you to try, as we have a great need for volunteers. I have also helped setting up the first MEARIM, in Egypt, and for this I am very pleased, as it was successful and will soon become a tradition at IAU.

But of course the highpoint of my presidency was the preparations and the launch of the International Year of Astronomy 2009 (IYA 2009). One of my early tasks was to lead the IAU delegation that went to New York, at the end of 2007, to lobby in favour of IYA at the United Nations. It was a momentous time. We were delighted to see that our proposal was extremely 
well received, and indeed the UN endorsement soon followed. In 2006 the Executive Committee established an IYA Working Group. I felt that this task was so important, in the years of my presidency, that I held the Chair of the Working Group, with the IAU Press Officer, Lars Christensen, as super efficient secretary. We soon agreed on the necessity of establishing an IYA Secretariat in charge of the global coordination of the activities. I was at ESO at the time, and we decided to put it at ESO, managed by Lars. We hired Pedro Russo, and later Mariana Barrosa, and, I am tempted to say, the rest is history. I have enjoyed working on a regular basis with Lars, Pedro and Mariana. I am proud of the work accomplished and of the results obtained. I will continue chairing the Working Group till the end of next year, which will be devoted to an evaluation of IYA activities and impact. The exchanges and feedback with Single Points of Contact, chairs of Cornerstones and of Special projects, astronomers and amateurs, have been an incredibly rewarding personal experience which I will never forget.

One of the goals of IYA is: "Provide a modern image of science and scientists", and I'll end this farewell as IAU President with a quote from the British newspaper The Guardian, on its editorial page on IYA2009, Saturday 25 July 2009: "Astronomers around the world compete, co-operate and confer; they are a global community, in the richest sense of the term, and we owe to them our understanding of space and time, and light, and mass, and gravity: in a word, everything."

\section{Address by the incoming President}

\section{Professor Robert Williams}

We are now more than halfway through the International Year of Astronomy and near the end of the General Assembly. This is a good time to take stock of where we are as a community and an organization. Let me begin by saying that I have been impressed with the different ways that many of you have employed to bring astronomy and discovery to the public. The efforts at all levels have been impressive, and there are many contributions that merit acknowledgement. From my standpoint on the Executive Committee I must begin by thanking Catherine Cesarsky for her efforts, which repeatedly took her around the globe. Her energy on behalf of the IYA and the Union has been remarkable.

Also deserving of comment is the unusual dedication without fanfare of the job that Karel van der Hucht has done as General Secretary. The Paris office went through serious turmoil with the death of our longtime executive assistant, and the way that Karel kept his focus on the job was exemplary. As one of the people who stood to be most affected by a meltdown in the Paris office, I spent some days fearing the worst. It did not happen and Karel's and our new assistant Vivien Reuter's steadfast, knowledgeable attention to details was a key part of the current healthy state of the IAU.

Then, there are you, the members: the core of the Union. American filmmaker Woody Allen once remarked: 85percent of success is showing up. You showed up-both for the IAU and IYA activities. We hope you continue to show up because this Union has many worthy programs that need your ingenuity and work, and we hope you participate in those for which you have interest and expertise.

This is an appropriate time to ask ourselves: where should the Union head in the future? Which programs might be expanded, and what new initiatives might we think of undertaking? The Executive Committee has been discussing Union priorities for the past two years, and several relevant events took place at this General Assembly. The first was the revision to the Bye-Laws that in the future allows for electronic voting on non-budgetary matters. We are developing tools that will enable more electronic communication and interaction between the divisions and commissions and the Paris office to take place. There is a divergence of opinions on whether e-voting should be used for scientific issues. The Executive Committee is still debating this issue. The basic question is whether the virtue of inclusiveness of members who are not at the GA outweighs the disadvantage of not being present for a live debate of issues. Some of us feel that 
both features can be accommodated by supplementing the GA debate with electronic debates on our website for a period after the GA, which would allow all members to vote on scientific issues. The option of allowing electronic votes on certain issues such as division and commission elections will definitely be pursued.

Another significant event of this General Assembly has been the adoption of a long-range strategy for the IAU. At this GA we conducted a town hall meeting to discuss the Strategic Plan that a group of members appointed by the Executive Committee and led by Vice President George Miley has developed. The Plan is titled 'World Wide Development of Astronomy', and it has just been approved by you by means of a resolution. Astronomy development is not a new activity for the Union but we will be expanding our efforts in support of the development of astronomy, especially in the area of science education. Specifically, we are trying to arrange for the funding of a Global Development Office that will coordinate a range of activities around the world to be carried out by IAU members.

The International Year of Astronomy has demonstrated the value of engaging the public. The IYA has brought the IAU further into public outreach than ever before. The constant struggle between science and superstition has important consequences for society, therefore the IAU should be deeply involved in educating the public. For some years the IAU has carried out development activities through Commission 46 initiatives. The Executive Committee wants to strengthen our programs of International School for Young Astronomers (ISYA), Teaching for Astronomy Development (TAD), and World Wide Development of Astronomy (WWDA), which have made a large contribution to science education in many countries. In order to expand Union efforts in this area we plan to seek external funding.

The IAU will continue to support the professional astronomy community through our longstanding sponsorship of symposia and issuance of travel grants. A large fraction of Union resources continues to flow back to the members through these grants. This is because the success of the Union depends not so much on the officers and the Executive Committee as on you, the members. We need your participation, and especially the ideas and energy of early career astronomers. Please continue to put forth your ideas and push your initiatives to keep the IAU active. Our mission is to understand the universe and pass this along to society. In doing so we expose them to a way of thinking that pushes back superstition and confronts preconceived ideas when they are not supported by facts, teaching the importance of being open to new facts and concepts.

This, I believe, is our core mission and I look forward to working with you to accomplish it.

\section{Emblematic songs and rhythms of Brazil}

Performed by Atrás da Nota Choir (Rio de Janeiro City Hall) and Choir Association CPRM (Geological Survey of Brazil), conducted by Mario Assef, as performed in the Inaugural Program:

- Pantanal (Marcus Viana) - Arranged by Silvia Sobreira - Sinfonia. Evokes the myths and traditions of Pantanal, the Brazilian large central swampland ecosystem.

- Samba do Avião (Tom Jobim) - Arranged by Ju Cassu - Bossa Nova. This song celebrated the feeling of landing in Rio de Janeiro city after a long time away.

- A Voz do Morro (Zé Kéti) - Arranged by Marcos Leite - Samba. Tells about the importance of samba music as source of Brazilian happiness.

- Aquarela do Brasil (Ary Barroso) - Arranged by Jos Assunçäo Jr. - Samba Exaltaçäo. Exaltation song about Brazilian beautiful landscape and people.

- Lata dagua na Cabeça (Lus Antonio e J. Júnior) - Arranged by Marcos Leite. Samba. Talks about typical slum hard women and her dreams 
- Sabiá (Luiz Gonzaga and Zé Dantas) - Arranged by Silvia Sobreira - Baiäo Medley. Northeast Brazilian rhythmic that spread throughout Brazil with the forró dance, especially during June and July holidays.

- Cajuna (Caetano Veloso) - Arranged by Malu Cooper

- Patuscada de Gandi (Gilberto Gil) - Arranged by Marcos Leite - Afroxé. Afro-Brazilian rhythm from Bahia.

- Cidade Maravilhosa (André Filho) - Arranged by Silvia Sobreira Marcha Rancho. Anthem of Rio de Janeiro city. 